\title{
Lack of FSH support enhances LIF-STAT3 signaling in granulosa cells of atretic follicles in cattle
}

\author{
Gustavo Freitas Ilha, Monique T Rovani, Bernardo G Gasperin ${ }^{1}$, Alfredo Quites Antoniazzi, \\ Paulo Bayard Dias Gonçalves, Vilceu Bordignon ${ }^{2}$ and Raj Duggavathi ${ }^{2}$ \\ Laboratory of Biotechnology and Animal Reproduction - BioRep, Veterinary Hospital, Federal University of Santa \\ Maria, Santa Maria, Rio Grande do Sul, Brazil, ${ }^{1}$ Laboratory of Animal Reproduction - ReproPEL, Federal University of \\ Pelotas, Capão do Leão, Rio Grande do Sul, Brazil and ${ }^{2}$ Department of Animal Science, McGill University, \\ 21111 Lakeshore Road, Sainte Anne de Bellevue, Quebec, Canada H9X 3V9
}

Correspondence should be addressed to R Duggavathi; Email: raj.duggavathi@mcgill.ca or to V Bordignon; Email: vilceu.bordignon@mcgill.ca

\begin{abstract}
Subordinate follicles (SFs) of bovine follicular waves undergo atresia due to declining FSH concentrations; however, the signalling mechanisms have not been fully deciphered. We used an FSH-induced co-dominance model to determine the effect of FSH on signalling pathways in granulosa cells of the second-largest follicles (SF in control cows and co-dominant follicle (co-DF2) in FSH-treated cows). The SF was smaller than DF in control cows while diameters of co-DF1 and co-DF2 in FSH-treated cows were similar. The presence of cleaved CASP3 protein confirmed that granulosa cells of SFs, but not of DFs and co-DFs, were apoptotic. To determine the effect of FSH on molecular characteristics of the second-largest follicles, we generated relative variables for the second largest follicle in each cow. For this, variables of SF or co-DF2 were divided by the variables of the largest follicle DF or co-DF1 in each cow. There was higher transcript abundance of $M A P K 1 / 3$ and $A K T 1 / 2 / 3$ but lower abundance of phosphorylated MAPK3/1 in SF than co-DF2 granulosa cells. Abundance of mRNA and phosphorylated protein of STAT3 was higher in granulosa cells of control SF than FSH-treated co-DF2. SF granulosa cells had higher levels of LIFR and IL6ST transcripts, the two receptors involved in STAT3 activation. Further, lower transcript abundance of interleukin 6 receptor (IL6R), another receptor involved in STAT3 activation, indicated that STAT3 activation in SF granulosa cells could be mainly due to leukemia inhibitory factor (LIF) signalling. These results indicate that atresia due to lack of FSH is associated with activated LIF-STAT3 signalling in SF granulosa cells, as FSH treatment reversed such activation.
\end{abstract}

Reproduction (2015) 150 395-403

\section{Introduction}

Even though bovine ovaries contain thousands of follicles, only $\sim 1 \%$ of them ovulate and contribute to the reproductive performance of a cow. As atresia is the most common outcome of follicular development, aberrant atresia will have a significant impact on fertility.

During the follicular wave, small follicles begin to grow together in response to a transient peak in circulating follicle-stimulating hormone (FSH) concentrations (Adams 1999, Adams et al. 2008). But only one follicle, selected to be dominant, continues to growth despite FSH levels reaching nadir while the others undergo atresia (Ginther et al. 1999). Follicular atresia is initiated with apoptosis of granulosa cells (Matsuda et al. 2012), which has been attributed to the depletion of survival factors, including FSH. In addition, follicular atresia requires a stimulatory component such as pro-apoptotic signals, because apoptosis must be localized to the atretic but not all other follicles.

Several studies have examined the role of protein kinase B (AKT) and MAPKs in granulosa cells, mostly using in vitro culture models (Seger et al. 2001, Ryan et al. 2008). Gonadotropins have been shown to activate AKT and MAPK signalling in granulosa cells (Babu et al. 2000, Zeleznik et al. 2003) and these pathways are considered important for dominant follicle (DF) selection (Evans \& Martin 2000, Gasperin et al. 2014). STAT is a family of proteins known to mediate signalling of cytokines and stimulate cell proliferation, differentiation and apoptosis (Levy \& Darnell 2002, Rawlings et al. 2004). The role of the STAT signalling pathway in mammalian folliculogenesis remains relatively uncharacterized (Sobinoff et al. 2013). Our recent study demonstrated increased phosphorylation of STAT3 in granulosa cells of atretic follicles collected on day 4 of 
the follicular wave, and proposed that this pathway may be involved in granulosa cell apoptosis during atresia (Gasperin et al. 2014). However, that study did not establish a causal relationship between declines in FSH concentrations and the activation of STAT3. Additionally, the identity of a stimulatory signal that may activate STAT3 when the FSH concentrations are low remains to be established. Some factors such as the Fas ligand (FASLG) have been proposed to be involved in granulosa cell apoptosis. While the FASLG has been shown in atretic follicles, its treatment alone does not induce granulosa cell apoptosis in vitro (Porter et al. 2000). This indicates that other signalling pathways such as the STAT3 pathway may contribute to follicular atresia. In this context, another ligand, leukemia inhibitory factor (LIF), has been shown to play a central role in apoptosis through activating STAT3 by phosphorylation during mammary gland involution (Kritikou et al. 2003).

FSH-induced co-DF model in cattle is an excellent model for comparison of DFs, subordinate follicles (SFs) and co-DFs. Molecular differences present between the second-largest follicles - SF in control animals and co-DF2 in FSH-treated cows - will provide a mechanistic basis for follicular atresia during the decline of $\mathrm{FSH}$ concentrations. The results of this study could potentially contribute to developing novel therapeutic measures to enhance follicular development during assisted reproductive technologies (ARTs). Therefore, the aim of our study was to test if signalling pathways and their cytokine activators are differentially regulated in granulosa cells of SF and co-DF2.

\section{Materials and methods \\ Co-DF induction and granulosa cell collection}

All experimental procedures using cattle were approved by the Federal University of Santa Maria Animal Care and Use Committee (ACUC no. 23081.009594/2007-41). Cyclic adult beef cows ( $n=20 ; 4-10$ years old) were synchronized as described previously (Gasperin et al. 2014). Eight cows with synchronous estrus were then used to carry out FSH or saline treatment during the first follicular wave. The ovaries of each cow were examined daily by transrectal ultrasonography and the day of ovulation was considered day 0 . On the second day after ovulation (day 2), saline (control group, $n=4$ ) or a total dose of $100 \mathrm{mg}$ FSH (FSH group, $n=4$, Folltropin-V; Bioniche Animal Health, Belleville, ON, Canada) was administered i.m. every $12 \mathrm{~h}$ for $48 \mathrm{~h}$. The total dose of FSH was divided into two doses of $30 \mathrm{mg}$ on day 2 and two doses of $20 \mathrm{mg}$ on day 3 . Ovaries were collected by colpotomy $12 \mathrm{~h}$ after the last FSH/ saline treatment (morning of day 4). The two largest follicles were dissected out from the ovaries and granulosa cells were harvested. The largest and the second-largest follicles were respectively classified as DF and SF in control cows, and co-DF1 and co-DF2 in FSH cows. Relative variable (RV) was calculated for all molecular data to determine the effect of FSH treatment, as detailed below in the 'Data processing and statistical analyses' section.

\section{RNA extraction, $R T$ and real-time PCR}

Total RNA and protein from granulosa cells were extracted using AllPrep DNA/RNA/Protein Kit (Qiagen) as described previously (Gasperin et al. 2014). Quantity and RNA purity were measured using the NanoDrop (Thermo Scientific, Waltham, MA, USA). Absorbance 260/280 nm ratios above 1.8 were considered pure, and all samples used in the present study were above this threshold. To synthesize cDNA, 500 ng RNA was first treated with $0.1 \cup$ DNAse (Invitrogen; $37^{\circ} \mathrm{C}-5 \mathrm{~min}$ ). After DNAse inactivation at $65^{\circ} \mathrm{C}$ for $10 \mathrm{~min}$, samples were incubated in a final volume of $20 \mu \mathrm{l}$ with iScript cDNA Synthesis Kit (Bio-Rad Laboratory) following the manufacturer's protocols.

Designing and validation of primers (Table 1) and qPCR were performed as described previously (Sanchez et al. 2014). Samples were run in duplicates and transcript levels for each gene of interest were expressed relative to the average abundance of the reference genes, CYCLOPHILIN and $G A P D H$. To test cross-contamination with theca cells, PCR for detection of the mRNAs that encode CYP17A1 in granulosa

Table 1 Primers used in the expression analysis of Bos taurus taurus genes.

\begin{tabular}{|c|c|c|}
\hline Gene & Primer sequence $\left(5^{\prime}-3^{\prime}\right)$ & $\begin{array}{l}\text { Conc } \\
(\mathrm{nM})\end{array}$ \\
\hline \multirow[t]{2}{*}{ CYCLOPHILIN } & F: GGTCATCGGTCTCTTTGGAA & 200 \\
\hline & R: TCCTTGATCACACGATGGAA & 200 \\
\hline \multirow[t]{2}{*}{ GAPDH } & F: ACCCAGAAGACTGTGGATGG & 200 \\
\hline & R: CAACAGACACGTTGGGAGTG & 200 \\
\hline \multirow[t]{2}{*}{ CYP19A1 } & F: GTGTCCGAAGTTGTGCCTATT & 200 \\
\hline & R: GGAACCTGCAGTGGGAAATGA & 200 \\
\hline \multirow[t]{2}{*}{ LHCGR } & F: GCACAGCAAGGAGACCAAATAA & 200 \\
\hline & R: TTGGGTAAGCAGAAACCATAGTCA & 200 \\
\hline \multirow[t]{2}{*}{ FSHR } & F: AGCCССТTGTCACAACTCTATGTC & 200 \\
\hline & R: GTTCCTCACCGTGAGGTAGATGT & 200 \\
\hline \multirow[t]{2}{*}{ CYP17A1 } & F: CCATCAGAGAAGTGCTCCGAAT & 200 \\
\hline & R: GCCAATGCTGGAGTCAATGA & 200 \\
\hline \multirow[t]{2}{*}{ STAT3 } & F: CTGCAGCAGAAGGTTAGCTACAAA & 200 \\
\hline & R: TTCTAAACAGCTCCACGATTCTCTC & 200 \\
\hline \multirow{2}{*}{ CCND2 } & F: TGCCССАGTGСТССТАСТTC & 200 \\
\hline & R: CGGGTACATGGCAAACTTGA & 200 \\
\hline \multirow{2}{*}{ CASP3 } & F: TGCAGAAGTCTGACTGGAAAACCCAAAC & 200 \\
\hline & R: TCATCСТCAGCACСАСТGTСТGTCTC & 200 \\
\hline \multirow[t]{2}{*}{ AKT1 } & F: GATTCTTCGCCAGCATCGTG & 300 \\
\hline & R: GGCCGTGAACTCCTCATCAA & 200 \\
\hline \multirow[t]{2}{*}{ AKT2 } & F: GCCGAATAGGAGAACTGGGG & 200 \\
\hline & R: CACGTCTGAGGTCGACACAA & 200 \\
\hline \multirow[t]{2}{*}{ AKT3 } & F: GTGGCGCACACTTTAACTGA & 200 \\
\hline & R: ACCCGCTCTCTCGACAAATG & 200 \\
\hline \multirow[t]{2}{*}{ MAPK1 } & F: TATTCGAGCACCGACCATCG & 200 \\
\hline & R: TGGAAGGTTTGAGGTCACGG & 200 \\
\hline \multirow[t]{2}{*}{ MAPK3 } & F: ACCCAAGGAACGACTGAAGG & 200 \\
\hline & R: GCTGGGCACACAGTCCATTT & 200 \\
\hline \multirow[t]{2}{*}{ LIFR } & F: AAACTGCCGGCATCTAAGGT & 200 \\
\hline & R: TCATGAGGTTGCTGGGACAG & 200 \\
\hline \multirow[t]{2}{*}{ IL6ST } & F: AGAGTGGGACСАССТTССТА & 200 \\
\hline & R: TCTGTGTAGGCTGCCATTCG & 200 \\
\hline \multirow[t]{2}{*}{ IL6R } & F: GACCAGAGGACAATGCCACA & 200 \\
\hline & R: TCACTCTACTGAGGGGGCTC & 200 \\
\hline
\end{tabular}

F, forward primer; $R$, reverse primer; Conc., primer concentration used for gene amplification. 
Table 2 Follicular diameter $(\mathrm{mm})$ determined by transrectal ultrasonography.

\begin{tabular}{llclc}
\hline Group & Follicle & Day 3 & Day 4 & Growth rate \\
\hline Control & DF & $6.3 \pm 1.5$ & $9.5 \pm 1.3$ & $3.2 \pm 0.8$ \\
& SF & $6.0 \pm 1.1$ & $6.1 \pm 0.6^{*}$ & $0.1 \pm 0.6^{*}$ \\
FSH & CO-DF1 & $5.3 \pm 0.6$ & $8.6 \pm 0.9$ & $3.4 \pm 0.3$ \\
& co-DF2 & $4.7 \pm 0.7$ & $7.5 \pm 0.7$ & $2.8 \pm 0.7$ \\
\hline
\end{tabular}

*Indicates significant difference from DF $(P<0.05)$.

cells was performed in each sample and all samples were free from contamination by theca cells (after 30 PCR cycles).

\section{Immunoblot analyses}

Granulosa cell protein samples obtained using AllPrep Kit (Qiagen) were boiled at $95{ }^{\circ} \mathrm{C}$ for $5 \mathrm{~min}$, subjected to $7.5 \%$ SDS gel and transferred onto nitrocellulose membranes. After blocking for $2 \mathrm{~h}$ with $5 \%$ skim milk in Tris-buffered saline (TBS) containing $0.1 \%$ Tween-20 (TBS-T), blots were incubated overnight at $4{ }^{\circ} \mathrm{C}$ with 1:1000 rabbit anti-human phosphorylated STAT3 (\#9131; Tyr 705; Cell Signaling Technology, Danvers, MA, USA), phosphorylated MAPK3/1 (\#4376; Erk1/2; Thr202/Tyr204; Cell Signaling Technology), phosphorylated AKT (\#2965; Thr308; Cell Signaling Technology), total STAT3 (\#9132; Cell Signaling Technology), total MAPK3/1 (\#4695; Erk1/2; Cell Signaling Technology), cleaved CASPASE3 (Asp175; \#9661, Cell Signaling Technology) or 1:5000 $\beta$-actin (bACTIN; ab8227; Abcam, Inc., Totonto, ON, Canada) with agitation, followed by three washes (10 min each) with TBS-T. The blots were then incubated with 1:7500 goat anti-rabbit IgG-HRP (ab6721; Abcam, Inc.) at room temperature for $2 \mathrm{~h}$ with agitation, followed by three washes (10 min each) with TBS-T. Immunoreactivity was detected with Immun-Star WesternC Chemiluminescence Kit (Bio-Rad Laboratory) according to the manufacturer's instructions and visualized using Chemidoc System (Bio-Rad Laboratory). Quantification of bands of the western blots was performed using Image Lab Software (Bio-Rad Laboratory). ERK1 and ERK2 band densities were added together and were represented as MAPK3/1. The abundance of phosphorylated proteins (pMAPK3/1, pAKT and pSTAT3) was calculated relative to their respective total protein levels. CASPASE total protein abundance was calculated relative to bACTIN.

\section{Data processing and statistical analysis}

Follicular dynamics data were analyzed by two-way ANOVA using SAS Software (SAS Institute, Inc., Cary, NC, USA). Differences between specific means were evaluated by the use of the Bonferroni's procedure on least squares means (Fricke et al. 1997). In order to determine the effect of FSH on molecular characteristics of the second largest follicles, we generated RVs for the second largest follicle in each cow. For this, variables of the second largest follicle (SF or co-DF2) in each cow were divided by the variables of the largest follicle (DF or co-DF1) from the same cow. RVs for mRNA data were compared between the two groups using the two-tailed Student's $t$-test. Based on the results of mRNA data analyses,
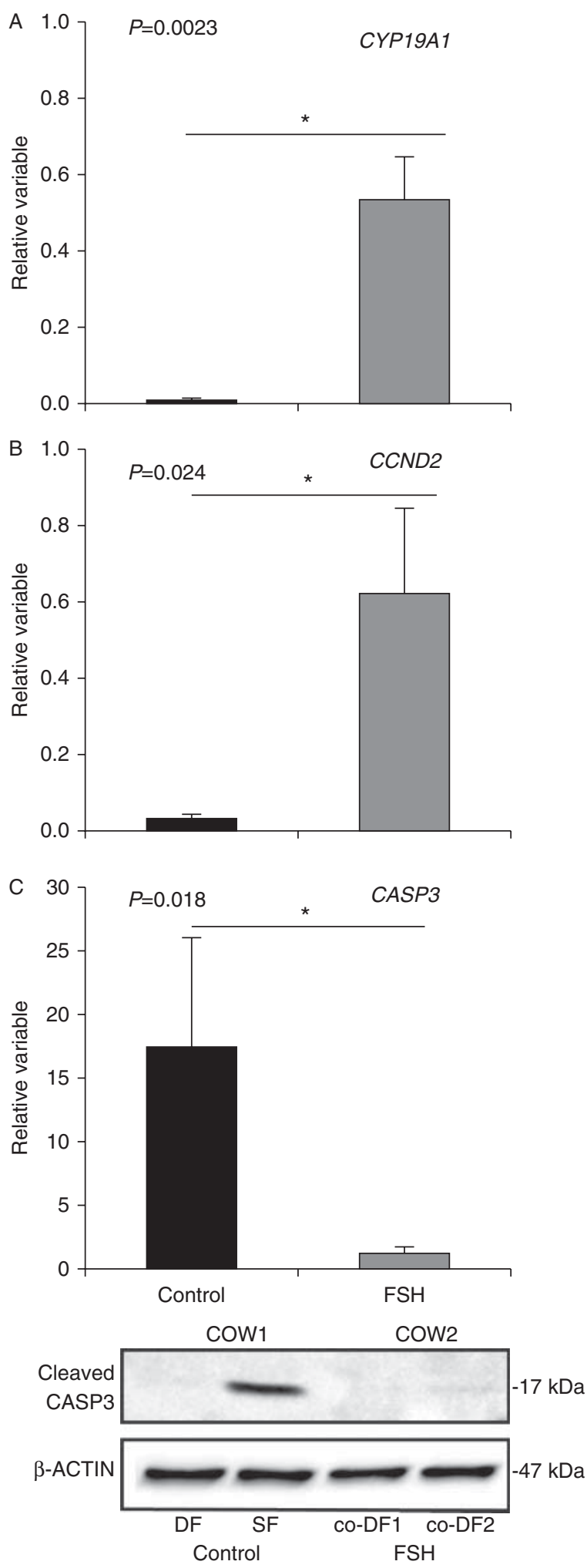

Figure 1 CYP19A1 (A), CCND2 (B) and CASP3 (C) mRNA expression and cleaved caspase 3 protein abundance (D) in granulosa cells of subordinate (SF) and co-dominant (Co-DF2) follicles. In order to determine the effect of FSH treatment, data for SF and co-DF2 were normalized to the data of DF and co-DF1 respectively. *Indicates statistical significance $(P<0.05)$. 
RVs for mRNA data were compared using one-tailed Student's $t$-test. Results are presented as mean \pm s.E.M. A $P<0.05$ was considered statistically significant.

\section{Results}

\section{Dynamics of the two largest follicles in control and FSH-treated cows}

Follicular dynamics measured by ultrasonography in control and FSH groups are shown in Table 2. As expected, the diameter of DF was larger than SF in control cows $(P<0.05)$ and there was no difference in diameters of co-DF1 and co-DF2 in FSH-treated cows $(P>0.05)$. The growth rate of DF, between days 3 and 4 after ovulation, was higher than that of SF in control cows $(P<0.05)$, whereas the growth rate of co-DF1 and CO-DF2 during this period was similar in FSH-treated cows $(P>0.05)$. Furthermore, the diameter and growth rate of Co-DFs of FSH-treated cows were similar to the DF of control cows $(P>0.05)$.
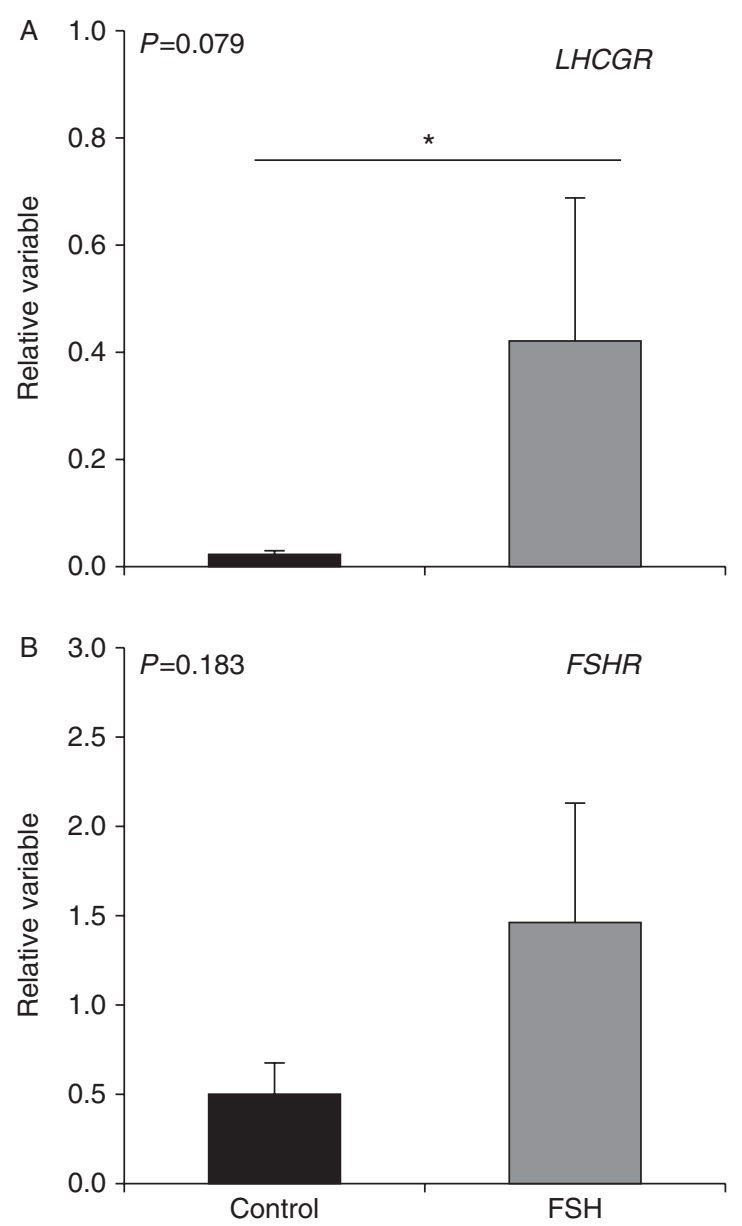

Figure 2 LHCGR (A) and FSHR (B) mRNA expression in granulosa cells of subordinate (SF) and co-dominant (co-DF2) follicles. In order to determine the effect of FSH treatment, data for SF and co-DF2 were normalized to the data of DF and co-DF1 respectively. *Indicates statistical significance $(P<0.05)$.
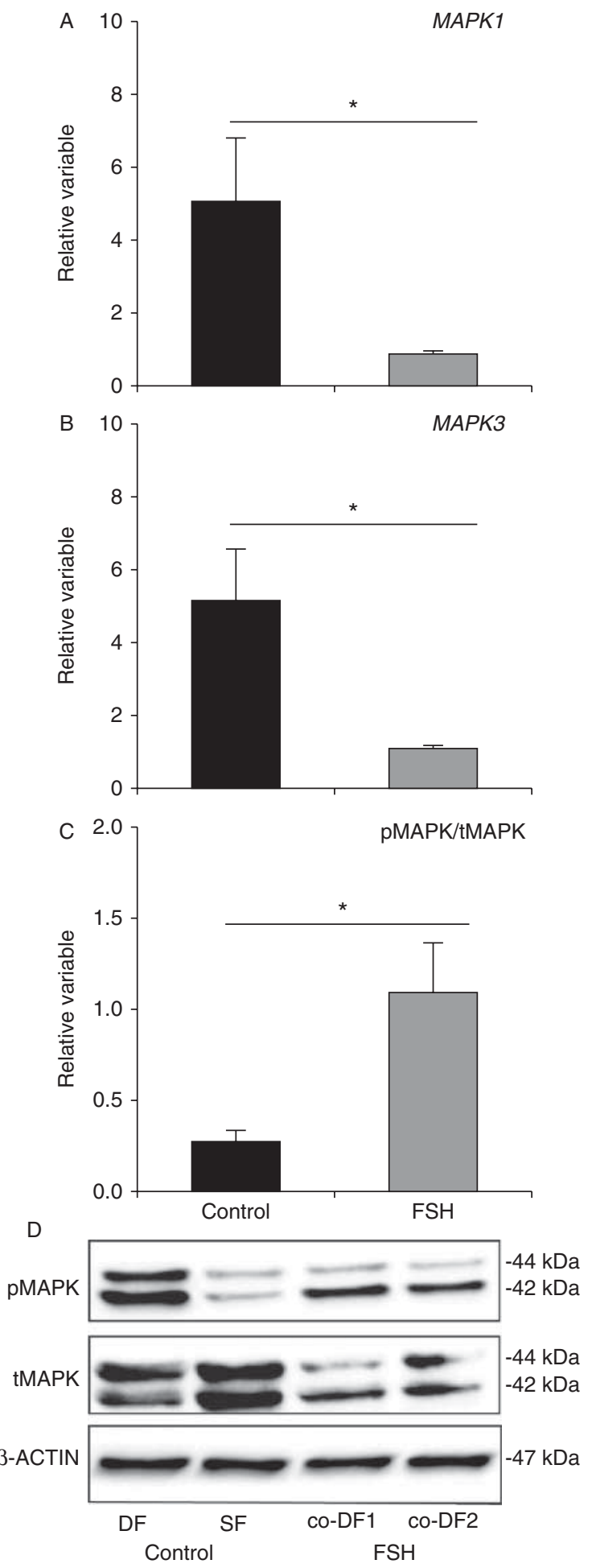

Figure $3 M A P K 1(\mathrm{~A})$ and $M A P K 3$ (B) mRNA expression and phosphorylated MAPK3/1 abundance (C) in granulosa cells of subordinate (SF) and co-dominant (co-DF2) follicles. In order to determine the effect of FSH treatment, data for SF and co-DF2 were normalized to the data of DF and co-DF1 respectively. (D) Representative immunoblots showing protein abundance of phosphorylated and total MAPK along with $\beta$-Actin in granulosa cells of different follicle groups. *Indicates statistical significance $(P<0.05)$. 


\section{Granulosa cell health in the two largest follicles from control and FSH-treated cows}

Granulosa cells were harvested from the two largest follicles of each of the saline and FSH-treated cows. To test if FSH treatment enhanced the health of granulosa cells of co-DF2 compared to SF, we analyzed CYP19A1 mRNA abundance in granulosa cells. As expected, mRNA abundance of CYP19A1 in granulosa cells of the SF was dramatically lower in control cows compared to Co-DF2 of $\mathrm{FSH}$-treated cows $(P<0.05$; Fig. $1 \mathrm{~A})$. Likewise, transcript levels of cyclin D2 (CCND2) were higher in co-DF2 than SF $(P<0.05$; Fig. 1B). On the other hand, CASP3 mRNA was more abundant in granulosa cells of SF in control cows than co-DF2 in FSH-treated cows ( $P<0.05$; Fig. 1C). Also, immunoblot assays revealed that the cleaved CASP3 protein was detected only in granulosa cells of SF but not in those of DF and co-DFs (Fig. 1D). Selection of the DF is associated with increased expression of gonadotropin receptors, especially LH receptor (LHCGR) in granulosa cells (Ginther et al. 1999). Thus, we evaluated the transcript abundance of gonadotropins receptors in granulosa cells. Relative mRNA abundance of $\angle H C G R$ was higher in co-DF2 than SF $(P<0.05$; Fig. 2A). Relative mRNA abundance of $F S H R$ in granulosa cells did not differ between follicles in control and FSH-treated cows (Fig. 2B).

\section{Phosphorylation status of MAPK3/1, AKT and STAT3 in granulosa cells of the two largest follicles in control and FSH-treated cows}

We first measured mRNA and protein levels of MAPK3/1, AKT and STAT3 in granulosa cells of the second largest follicles relative to the largest follicles from control and FSH-treated cows. Levels of MAPK1 and MAPK3 mRNA were higher in granulosa cells of SF of control cows than co-DF2 of FSH-treated cows $(P<0.05$; Fig. $3 \mathrm{~A}$ and $\mathrm{B})$. In contrast to the mRNA profile, the abundance of phosphorylated MAPK3/1 proteins was lower in granulosa cells of SF in control cows than co-DF2 in FSH-treated cows $(P<0.05$; Fig. 3C and D). Relative mRNA levels of AKT1, AKT2 and AKT3 were higher in control SF than FSH-treated co-DF2 $(P<0.05 ;$ Fig. 4A, B and $\mathrm{C}$ respectively). However, the abundance of phosphorylated AKT did not differ between the second-largest follicles of both groups $(P>0.05$; Fig. 4D and E), albeit FSH-treated Co-DF2 had numerically higher pAKT. Relative abundance of STAT3 mRNA was markedly higher in granulosa cells of SF than in co-DF2 $(P<0.05$; Fig. $5 \mathrm{~A})$. In line with the mRNA pattern, the relative abundance of both total and phosphorylated isoform of STAT3 protein was higher in granulosa cells of SF compared to co-DF2 $(P<0.05$; Fig. 5B, C and D).
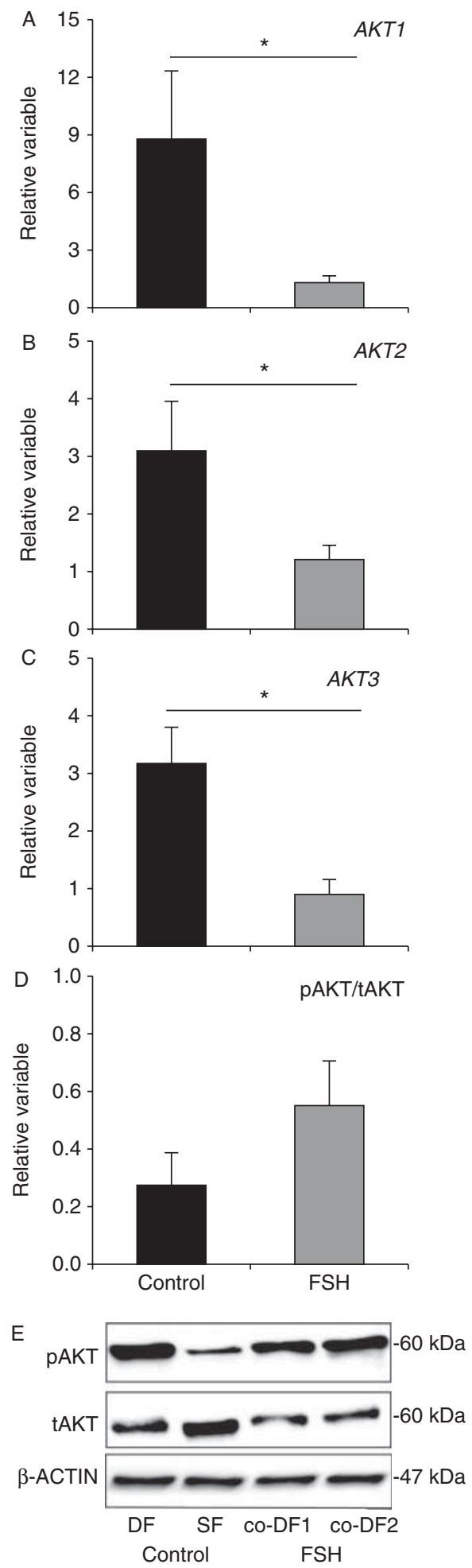

Figure $4 A K T 1$ (A), AKT2 (B) and $A K T 3(\mathrm{C})$ mRNA levels and phosphorylated $A K T$ abundance (D) in granulosa cells of subordinate (SF) and co-dominant (co-DF2) follicles. In order to determine the effect of FSH treatment, data for SF and co-DF2 were normalized to the data of DF and co-DF1 respectively. (E) Representative immunoblots showing protein abundance of phosphorylated and total AKT along with $\beta$-Actin in granulosa cells of different follicle groups. *Indicates statistical significance $(P<0.05)$. 

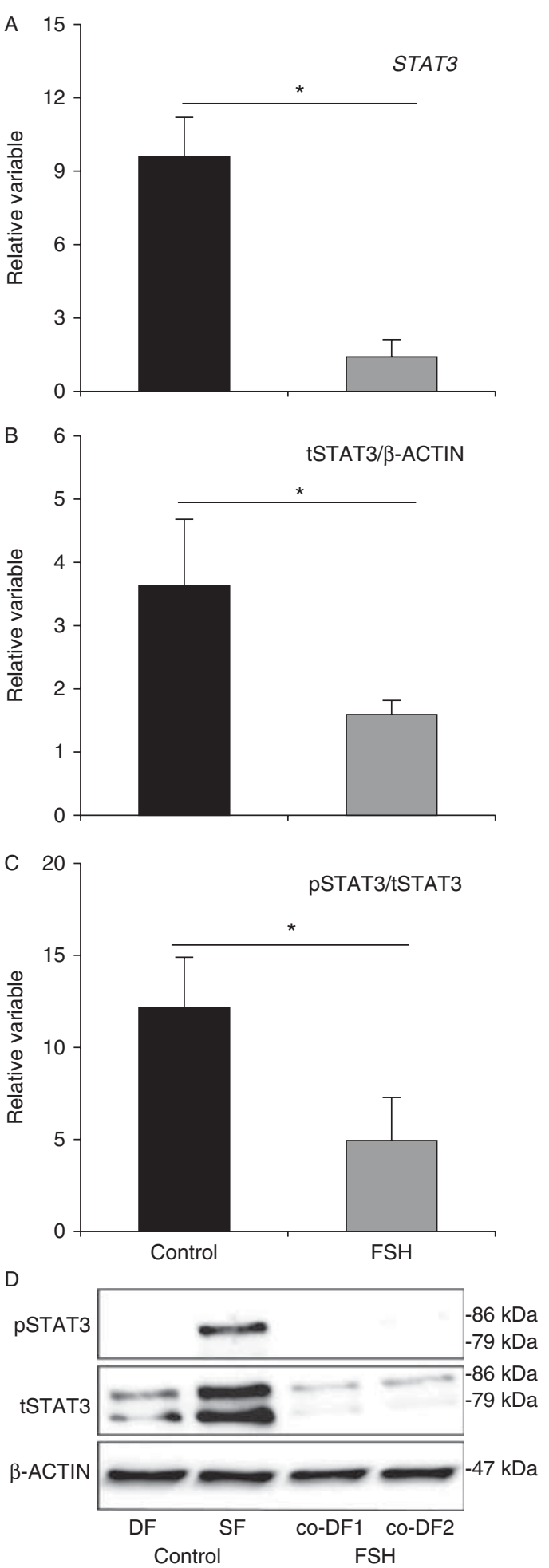

Figure 5 STAT3 mRNA abundance (A) and levels of total (B) and phosphorylated (C) STAT3 in granulosa cells of subordinate (SF in Control group) and co-dominant (co-DF2 in FSH group) follicles. In order to determine the effect of FSH treatment, data for SF and co-DF2 were normalized to the data of DF and co-DF1, respectively. (D) Representative immunoblots showing protein abundance of phosphorylated and total STAT3 with $\beta$-Actin in granulosa cells of different follicle groups. ${ }^{*}$ Indicates statistical significance $(P<0.05)$.

\section{Transcript abundance of the receptors of known STAT3-activating ligands in granulosa cells of the two largest follicles in control and $\mathrm{FSH}$-treated cows}

It is well established that leukaemia inhibitory factor (LIF) acting through its receptor (LIFR) stimulates STAT3 by phosphorylation (Heinrich et al. 1998). Also, LIFR forms heterodimers with the glycoprotein IL6ST to form a high affinity receptor through which LIF signaling is triggered (Heinrich et al. 1998). In line with the activation of STAT3, LIFR and IL6ST mRNA levels were higher in granulosa cells of control SF than FSH-treated co-DF2 $(P<0.05$; Fig. $6 \mathrm{~A}$ and $\mathrm{B}$ respectively). On the other hand, mRNA levels of interleukin 6 receptor (IL6R), which competes with LIFR to form heterodimers with IL6ST for STAT3 activation, were lower in SF than co-DF2 $(P<0.05$; Fig. 6C).

\section{Discussion}

Understanding the molecular mechanisms involved in atresia of follicles in response to declining $\mathrm{FSH}$ concentrations is important for developing novel methods to enhance follicular development during ARTs. SFs undergo atresia due to declining FSH (Rivera \& Fortune 2001, Lopez et al. 2005). Our recent study demonstrated that the STAT3 signalling pathway is activated in granulosa cells of atretic SFs (Gasperin et al. 2014). These temporal data did not establish that lack of FSH concentrations resulted in activation of STAT3. In the present study, we used a FSH-induced co-DF model to investigate signalling pathways in granulosa cells of SFs and examined if altered pathways of SFs are rescued in the second-largest follicle that would have undergone atresia in FSH-treated cows. Administration of small doses of FSH at the expected time of follicular deviation prevents the decline in $\mathrm{FSH}$ levels and thus one or more SFs escape atresia to become co-DFs (Mihm et al. 1997, Rivera \& Fortune 2001). Indeed, in FSH-treated cows of the present study, the two largest follicles continued growing at a similar growth rate and did not differ in size. There were no significant differences in FSHR mRNA abundance in granulosa cells from the second largest follicles in both groups. Taken together with the previous observations (Luo et al. 2011, Gasperin et al. 2014), these data indicate that the presence FSHR alone does not rescue the SF from atresia. The $L H C G R$ mRNA levels were lower in SFs relative to DFs compared to co-DF2 relative to co-DF1. These data are similar to previous reports (Beg et al. 2001, Luo et al. 2011) and together indicate that FSH-induced LHCGR prevented the potential SF from undergoing atresia in response to declining FSH concentrations. The lower LHCGR expression in SFs was associated with a remarkable increase in the mRNA abundance of CASP3 and cleaved CASP3 protein. FSH treatment inhibited CASP3 expression and cleavage in granulosa 
cells of co-DF2. These results suggest that follicular atresia in low FSH environment involves induction of CASP3 expression and cleavage, leading to granulosa cell apoptosis.
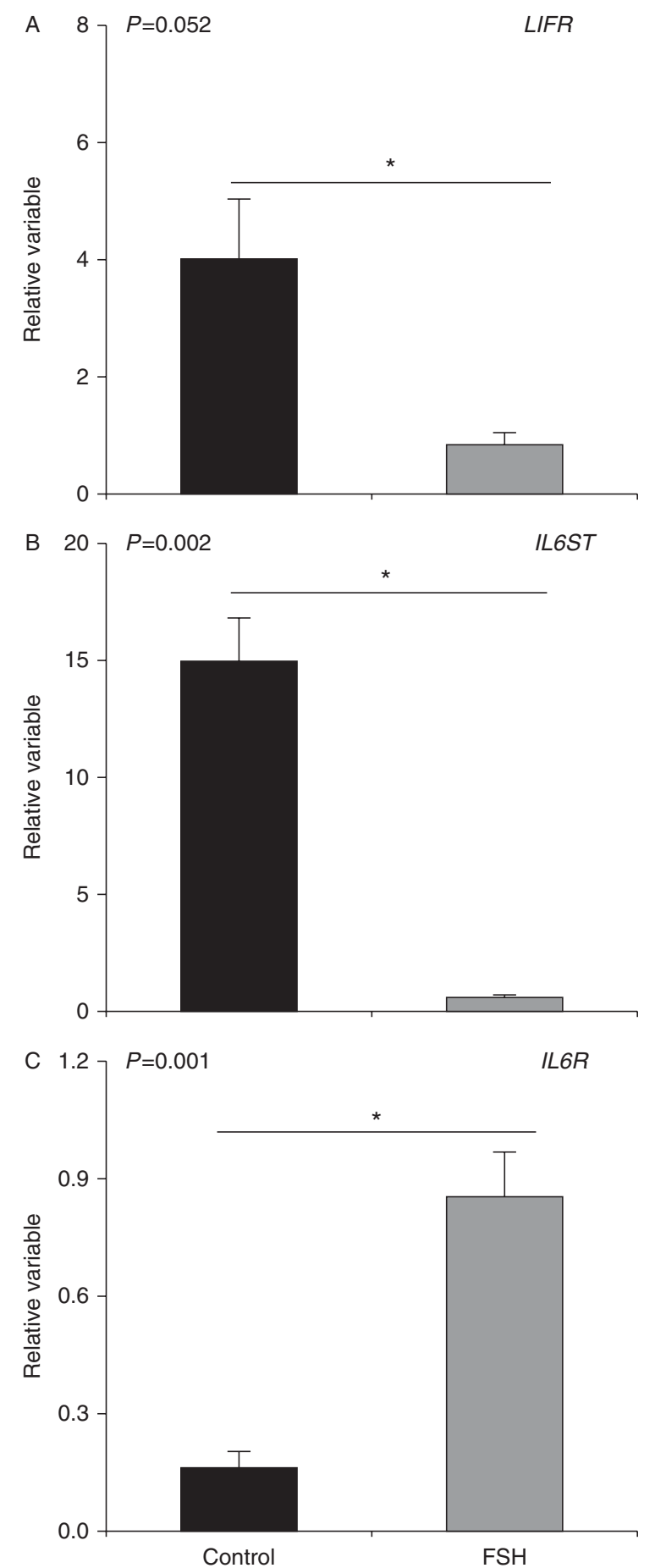

Figure $6 \operatorname{LIFR}(\mathrm{A}), \operatorname{IL} 6 S T(\mathrm{~B})$ and IL6R $(\mathrm{C})$ mRNA expression in granulosa cells of subordinate (SF) and co-dominant (co-DF) follicles. In order to determine the effect of FSH treatment, data for SF and co-DF2 were normalized to the data of DF and co-DF1 respectively. *Indicates statistical significance $(P<0.05)$.
STATs are a family of transcription factors that mediate cytokine signalling and stimulate cell proliferation, migration and apoptosis (Levy \& Darnell 2002, Rawlings et al. 2004). The receptors of cytokines such as LIF and IL6 share a common transmembrane protein receptor, IL6ST (a.k.a. gp130) to activate STATs (Heinrich et al. 1998). After ligand binding of the receptor, STATs become activated through tyrosine phosphorylation and regulate transcription (Bromberg \& Darnell 2000). In the present study, phospho-STAT3 protein and mRNA levels were high in granulosa cells from SF, confirming our previous observations (Gasperin et al. 2014). We further found that in high $\mathrm{FSH}$ environment of $\mathrm{FSH}$ treated cows, there was no such activation of STAT3 in granulosa cells of co-DF2, suggesting that FSH treatment inhibits activation of STAT3. The increased phosphoSTAT3 abundance in granulosa cells of SF suggests that this pathway is potentially activated by factors involved in the inhibition of granulosa cell estradiol synthesis, proliferation and/or differentiation.

A switch from survival to death signalling induces physiological apoptosis. Deletion of STAT3 resulted in reduced levels of apoptosis and delayed mammary gland involution (Chapman et al. 1999, Kritikou et al. 2003). Therefore, our current data support the hypothesis that STAT3 signalling pathway is involved in granulosa cell apoptosis during atresia and that its suppression is one of the mechanisms by which FSH supports follicular development in cows.

Inhibition of AKT and MAPK pathways abrogates the stimulatory actions of FSH and insulin-like growth factor (IGF) on cultured bovine granulosa cells (Ryan et al. 2008). We found that despite high expression of MAPK1/ 3 and AKT1/2/3, the phosphorylated isoforms of these proteins were lower in granulosa cells of control SF than FSH-treated co-DF2. Higher levels of pAKT and pMAPK proteins were shown in the follicle wall of DFs in cattle (Evans \& Fortune 1997) and sheep (Evans \& Martin 2000). Our observations that the co-DF2 in FSH-treated cows had higher amounts of pMAPK and pAKT proteins suggest that FSH maintains AKT and MAPK protein activity in growing co-DFs.

The deprivation of key survival factors or stimulation by death ligands are the main causes of apoptosis and both contribute to granulosa cell apoptosis (MatsudaMinehata et al. 2006). Estradiol, IGF1, FSH, epidermal growth factor and IL6 have been characterized as antiapoptotic factors (Hsu \& Hammond 1987, Chun et al. 1995, Hsu \& Hsueh 1997, Heinrich et al. 1998, Rosenfeld et al. 2001, Mao et al. 2004). These factors act by activating the AKT signalling pathway (Matsuda et al. 2012). On the other hand, the death ligandreceptor systems such as FASLG, Fas (CD95), tumour necrosis factor alpha (TNF $\alpha$ and its receptor TNFR) and BCL2 family proteins have been implicated in follicular atresia (Baud \& Karin 2001, Matsuda-Minehata et al. 2006, Jaaskelainen et al. 2009, Matsuda et al. 2012). 
These signals induce different intracellular pro-apoptotic pathways, which result in cleavage of CASP3 leading to apoptosis (Matsuda et al. 2012).

LIF is a STAT3 activating ligand that has been shown to play a role in the apoptotic process during the mammary gland involution (Kritikou et al. 2003). LIF/STAT3 signalling coincides with induction of apoptosis in mammary epithelial cells (Abell et al. 2005). Our results demonstrated a positive association of higher mRNA levels of LIFR, IL6ST and STAT3 with increased STAT3 activity in SF granulosa cells. On the other hand, IL6R mRNA abundance was lower in SF granulosa cells. As both LIFR and IL6R require dimerization with IL6ST for their signalling, the expression pattern of these three receptors suggests that there is an overall increase in LIFR signalling while IL6R signalling is reduced. These results suggest that LIF may be the primary ligand activating the STAT3 pathway in granulosa cells undergoing apoptosis. Our study is the first to suggest that LIF/STAT3 signaling may play a role in granulosa cell apoptosis. Further mechanistic studies are required to identify the relationship between the three signaling pathways, MAPK, AKT and STAT3, in ovarian granulosa cells, as well as to identify the origin of LIF in atretic follicles.

In summary, atresia of SF was associated with increased STAT3 phosphorylation, which could be attributed to an increased expression of LIFR and IL6ST in granulosa cells. Such increased STAT3 signalling was inhibited by the FSH treatment in granulosa cells of co-DF2. Temporal relationship between phosphorylated STAT3 and cleaved CASP3 in granulosa cells of SFs indicates that an increase in STAT3 signalling may be involved in apoptosis during follicular atresia. We conclude that FSH treatment rescued granulosa cells of co-DF2 through inhibition of STAT3 pathways. Further studies are required to delineate the mechanisms by which declining FSH concentrations result in increased LIF-STAT3 signalling in granulosa cells of SFs. It would also be interesting to study the potential contribution of STAT3 in ovarian dysfunction in lactating dairy cows.

\section{Declaration of interest}

The authors declare that there is no conflict of interest that could be perceived as prejudicing the impartiality of the research reported.

\section{Funding}

This study was supported by Coordenação de Aperfeiçoamento de Pessoal de Nível Superior (CAPES-Brazil), Conselho Nacional de Desenvolvimento Científico e Tecnológico (CNPq-Brazil) and the Natural Sciences and Engineering Research Council (NSERC-Canada).

\section{Acknowledgements}

The authors are thankful to Dr Olmiro de Andrade Neto for providing the animals and UFSM and McGill University facilities for providing laboratory space.

\section{References}

Abell K, Bilancio A, Clarkson RW, Tiffen PG, Altaparmakov AI, Burdon TG, Asano T, Vanhaesebroeck B \& Watson CJ 2005 Stat3-induced apoptosis requires a molecular switch in $\mathrm{PI}(3) \mathrm{K}$ subunit composition. Nature Cell Biology 7 392-398. (doi:10.1038/ncb1242)

Adams GP 1999 Comparative patterns of follicle development and selection in ruminants. Journal of Reproduction and Fertility. Supplement $\mathbf{5 4}$ $17-32$.

Adams GP, Jaiswal R, Singh J \& Malhi P 2008 Progress in understanding ovarian follicular dynamics in cattle. Theriogenology 69 72-80. (doi:10. 1016/j.theriogenology.2007.09.026)

Babu PS, Krishnamurthy H, Chedrese PJ \& Sairam MR 2000 Activation of extracellular-regulated kinase pathways in ovarian granulosa cells by the novel growth factor type 1 follicle-stimulating hormone receptor. Role in hormone signaling and cell proliferation. Journal of Biological Chemistry 275 27615-27626. (doi:10.1074/jbc.M003206200)

Baud V \& Karin M 2001 Signal transduction by tumor necrosis factor and its relatives. Trends in Cell Biology 11 372-377. (doi:10.1016/S09628924(01)02064-5)

Beg MA, Bergfelt DR, Kot K, Wiltbank MC \& Ginther OJ 2001 Follicularfluid factors and granulosa-cell gene expression associated with follicle deviation in cattle. Biology of Reproduction 64 432-441. (doi:10.1095/ biolreprod64.2.432)

Bromberg J \& Darnell JE Jr 2000 The role of STATs in transcriptional control and their impact on cellular function. Oncogene 19 2468-2473. (doi:10.1038/sj.onc.1203476)

Chapman RS, Lourenco PC, Tonner E, Flint DJ, Selbert S, Takeda K, Akira S, Clarke AR \& Watson CJ 1999 Suppression of epithelial apoptosis and delayed mammary gland involution in mice with a conditional knockout of Stat3. Genes and Development 13 2604-2616. (doi:10.1101/gad.13. 19.2604)

Chun SY, Eisenhauer KM, Kubo M \& Hsueh AJ 1995 Interleukin-1 $\beta$ suppresses apoptosis in rat ovarian follicles by increasing nitric oxide production. Endocrinology 136 3120-3127. (doi:10.1210/endo.136.7. 7540548)

Evans AC \& Fortune JE 1997 Selection of the dominant follicle in cattle occurs in the absence of differences in the expression of messenger ribonucleic acid for gonadotropin receptors. Endocrinology $\mathbf{1 3 8}$ 2963-2971. (doi:10.1210/endo.138.7.5245)

Evans AC \& Martin F 2000 Kinase pathways in dominant and subordinate ovarian follicles during the first wave of follicular development in sheep. Animal Reproduction Science 64 221-231. (doi:10.1016/S03784320(00)00210-4)

Fricke PM, al-Hassan MJ, Roberts AJ, Reynolds LP, Redmer DA \& Ford JJ 1997 Effect of gonadotropin treatment on size, number, and cell proliferation of antral follicles in cows. Domestic Animal Endocrinology 14 171-180. (doi:10.1016/S0739-7240(97)00006-4)

Gasperin BG, Rovani MT, Ferreira R, Ilha GF, Bordignon V, Gonçalves PBD \& Duggavathi R 2014 Functional status of STAT3 and MAPK3/1 signaling pathways in granulosa cells during bovine follicular deviation. Theriogenology 83 353-359. (doi:10.1016/j.theriogenology.2014.09.026)

Ginther OJ, Bergfelt DR, Kulick LJ \& Kot K 1999 Selection of the dominant follicle in cattle: establishment of follicle deviation in less than 8 hours through depression of FSH concentrations. Theriogenology $\mathbf{5 2}$ 1079-1093. (doi:10.1016/S0093-691X(99)00196-X)

Heinrich PC, Behrmann I, Muller-Newen G, Schaper F \& Graeve L 1998 Interleukin-6-type cytokine signalling through the gp130/Jak/STAT pathway. Biochemical Journal 334 297-314. (doi:10.1042/bj3340297)

Hsu CJ \& Hammond JM 1987 Gonadotropins and estradiol stimulate immunoreactive insulin-like growth factor-I production by porcine granulosa cells in vitro. Endocrinology 120 198-207. (doi:10.1210/endo-120-1-198) 
Hsu SY \& Hsueh AJ 1997 Hormonal regulation of apoptosis an ovarian perspective. Trends in Endocrinology and Metabolism 8 207-213. (doi:10.1016/S1043-2760(97)00036-2)

Jaaskelainen M, Kyronlahti A, Anttonen M, Nishi Y, Yanase T, Secchiero P, Zauli G, Tapanainen JS, Heikinheimo M \& Vaskivuo TE 2009 TRAIL pathway components and their putative role in granulosa cell apoptosis in the human ovary. Differentiation 77 369-376. (doi:10.1016/j.diff. 2008.12.001)

Kritikou EA, Sharkey A, Abell K, Came PJ, Anderson E, Clarkson RW \& Watson CJ 2003 A dual, non-redundant, role for LIF as a regulator of development and STAT3-mediated cell death in mammary gland. Development 130 3459-3468. (doi:10.1242/dev.00578)

Levy DE \& Darnell JE Jr 2002 Stats: transcriptional control and biological impact. Nature Reviews. Molecular Cell Biology 3 651-662. (doi:10. 1038/nrm909)

Lopez H, Sartori R \& Wiltbank MC 2005 Reproductive hormones and follicular growth during development of one or multiple dominant follicles in cattle. Biology of Reproduction 72 788-795. (doi:10.1095/ biolreprod.104.035493)

Luo W, Gumen A, Haughian JM \& Wiltbank MC 2011 The role of luteinizing hormone in regulating gene expression during selection of a dominant follicle in cattle. Biology of Reproduction 84 369-378. (doi:10.1095/biolreprod.110.085274)

Mao J, Smith MF, Rucker EB, Wu GM, McCauley TC, Cantley TC, Prather RS, Didion BA \& Day BN 2004 Effect of epidermal growth factor and insulinlike growth factor I on porcine preantral follicular growth, antrum formation, and stimulation of granulosal cell proliferation and suppression of apoptosis in vitro. Journal of Animal Science 82 1967-1975.

Matsuda F, Inoue N, Manabe N \& Ohkura S 2012 Follicular growth and atresia in mammalian ovaries: regulation by survival and death of granulosa cells. Journal of Reproduction and Development 58 44-50. (doi:10.1262/jrd.2011-012)

Matsuda-Minehata F, Inoue N, Goto Y \& Manabe N 2006 The regulation of ovarian granulosa cell death by pro- and anti-apoptotic molecules. Journal of Reproduction and Development 52 695-705. (doi:10.1262/ jrd.18069)

Mihm M, Good TE, Ireland JL, Ireland JJ, Knight PG \& Roche JF 1997 Decline in serum follicle-stimulating hormone concentrations alters key intrafollicular growth factors involved in selection of the dominant follicle in heifers. Biology of Reproduction 57 1328-1337. (doi:10.1095/ biolreprod57.6.1328)
Porter DA, Vickers SL, Cowan RG, Huber SC \& Quirk SM 2000 Expression and function of Fas antigen vary in bovine granulosa and theca cells during ovarian follicular development and atresia. Biology of Reproduction 62 62-66. (doi:10.1095/biolreprod62.1.62)

Rawlings JS, Rosler KM \& Harrison DA 2004 The JAK/STAT signaling pathway. Journal of Cell Science 117 1281-1283. (doi:10.1242/jcs.00963)

Rivera GM \& Fortune JE 2001 Development of codominant follicles in cattle is associated with a follicle-stimulating hormone-dependent insulin-like growth factor binding protein-4 protease. Biology of Reproduction 65 112-118. (doi:10.1095/biolreprod65.1.112)

Rosenfeld CS, Wagner JS, Roberts RM \& Lubahn DB 2001 Intraovarian actions of oestrogen. Reproduction 122 215-226. (doi:10.1530/rep.0. 1220215)

Ryan KE, Glister C, Lonergan P, Martin F, Knight PG \& Evans AC 2008 Functional significance of the signal transduction pathways Akt and Erk in ovarian follicles: in vitro and in vivo studies in cattle and sheep. Journal of Ovarian Research 1 2. (doi:10.1186/1757-2215-1-2)

Sanchez R, Schuermann Y, Gagnon-Duval L, Baldassarre H, Murphy BD, Gevry N, Agellon LB, Bordignon V \& Duggavathi R 2014 Differential abundance of IGF1, bile acids, and the genes involved in their signaling in the dominant follicle microenvironment of lactating cows and nulliparous heifers. Theriogenology 81 771-779. (doi:10.1016/j.theriogenology.2014.01.005)

Seger R, Hanoch T, Rosenberg R, Dantes A, Merz WE, Strauss JF III \& Amsterdam A 2001 The ERK signaling cascade inhibits gonadotropinstimulated steroidogenesis. Journal of Biological Chemistry $\mathbf{2 7 6}$ 13957-13964. (doi:10.1074/jbc.M003766200)

Sobinoff AP, Sutherland JM \& McLaughlin EA 2013 Intracellular signalling during female gametogenesis. Molecular Human Reproduction 19 265-278. (doi:10.1093/molehr/gas065)

Zeleznik AJ, Saxena D \& Little-Ihrig L 2003 Protein kinase B is obligatory for follicle-stimulating hormone-induced granulosa cell differentiation. Endocrinology 144 3985-3994. (doi:10.1210/en.2003-0293)

Received 16 January 2015

First decision 1 March 2015

Revised manuscript received 3 July 2015

Accepted 29 July 2015 